\title{
On Services for Collaborative Project Management
}

\author{
Martin Ollus, Kim Jansson, Iris Karvonen, Mikko Uoti, and Heli Riikonen \\ VTT Technical Research Centre of Finland, Industrial Systems \\ Vuorimiehentie 5, \\ P O Box 1000, 02044 VTT, Finland \\ \{Martin.ollus, Kim.Jansson, Iris.Karvonen, Mikko.Uoti, \\ Heli.Riikonen\}@vtt.fi
}

\begin{abstract}
This paper presents an approach for collaborative project management. The focus is on the support of collaboration, communication and trust. Several project management tools exist for monitoring and control the performance of project tasks. However, support of important intangible assets is more difficult to find. In the paper a leadership approach is identified as a management means and the use of new IT technology, especially social media for support of leadership in project management is discussed.
\end{abstract}

Keywords: Project management, Distribution, Networking, Collaboration, Collaborative projects, Social Media, Software Services.

\section{Introduction}

Today, many business activities are performed as collaboration in networks. Dispersed partners come together to perform a specific task. Also projects consist of partners from a wide variety of organizations collaborating towards a common goal, despite of different background, culture and business behavior. The success of the project depends heavily on the collaborative performance. Project management consists to a large extent of the support and guidance for collaboration. In a distributed environment, the project management needs support from services for monitoring status and performance and for implementation of own actions.

A collaborative and distributed project has common features with a Virtual Organization, for which the operation and management support has been of interest in research recently [1]. This paper deals with the alignment of the partners' activities towards a common aim through "shared working practices" and "delegated and participatory project execution". It presents previous results achieved for management of distributed organizations (Virtual Organizations) and further development of these ones towards collaborative project management and leadership support.

The paper is structured as follows. First, we introduce some basic concepts and definitions in chapter 2 and the characteristics of collaborative project management, especially focusing on intangible assets of collaboration. In chapter 3, available IT support and the use of social media approaches for supporting collaboration in project management is discussed briefly. Chapter 4 outlines the application of services based on the combination of leadership management supported by social media based tools. 


\section{Collaborative Project Management}

\subsection{Concepts}

An early definition of management was given by Mary Parker Follett in the early twentieth century: "the art of getting things done through people" [2]. Other definitions consider the management to deal with "directing and controlling a group of one or more people or entities for the purpose of coordinating and harmonizing them towards accomplishing a goal". The management can consist of several dimensions, like human, financial, technological, resources etc.

Project Management is the discipline of planning, organizing, and managing resources to bring a successful completion of specific project goals and objectives. The primary challenge of project management is to achieve all of the project goals and objectives while adhering to classic project constraints - usually scope, quality, time and budget. The secondary — and more ambitious—challenge is to optimize the allocation and integration of inputs necessary to meet pre-defined objectives.

The Project Management Institute (www.pmi.org) has made a considerable work in collecting the Project Management Body of Knowledge $\left(\boldsymbol{P M B O K}{ }^{\circledR}\right)$. The $\boldsymbol{P M B O K}^{\circledR}$ Guide, one of the results, is an internationally recognized standard (IEEE Std 14902003) that provides the fundamentals of project management, as they apply to a wide range of projects. The PMBOK® Guide is process-based. It describes work as being accomplished by processes. The approach is consistent with other management standards such as ISO 9000 and the Software Engineering Institute's CMMI.

Another recognized body supporting the advancement of project management is The International Project Management Association, IPMA (http://www.ipma.ch), which is a world leading non-profit making project management organization. It certifies project managers, awards successful project teams and researchers, and provides a number of project management publications. IPMA also arranges the yearly World Congress on project management. IPMA E\&T Board has collected recommended literature in the project management area. Some publications also cover collaborative project management $[3,4,5]$.

The discipline of project management is well established and much good and relevant material is available. However, the focus is mainly on the management of project within a single enterprise and not for the management of dynamic collaborative projects. Despite of this fact, the large body of knowledge in the area can be used and extended to the complex domain of dynamic collaborative project management.

\subsection{Collaborative Project Management}

The term collaboration has been defined e.g. by Camarinha-Matos and Afsarmanesh as "a process in which entities share information, resources and responsibilities to jointly plan, implement, and evaluate a program of activities to achieve a common goal" [6]. The concept is derived from the Latin "collaborare" meaning "to work together" and refers to mutual engagement of participants to achieve the aims, indicating a close integration between the parties. Collaborative Project Management can be interpreted in two ways 
- Management of Collaborative Projects,

- Collaborative Management of Projects

Collaborative Management of Projects includes shared project management, which means delegation of management responsibility and some extent of self organization. The management may in many cases be non-hierarchical and participative with results based assessment of progress.

Management of Collaborative Projects mainly refers to the management of projects in networked and distributed environments. The processes are distributed with participants and organizations in different locations, countries and cultures. The management can be either central or collaborative. Figure 1 illustrates the interpretations of the concepts.

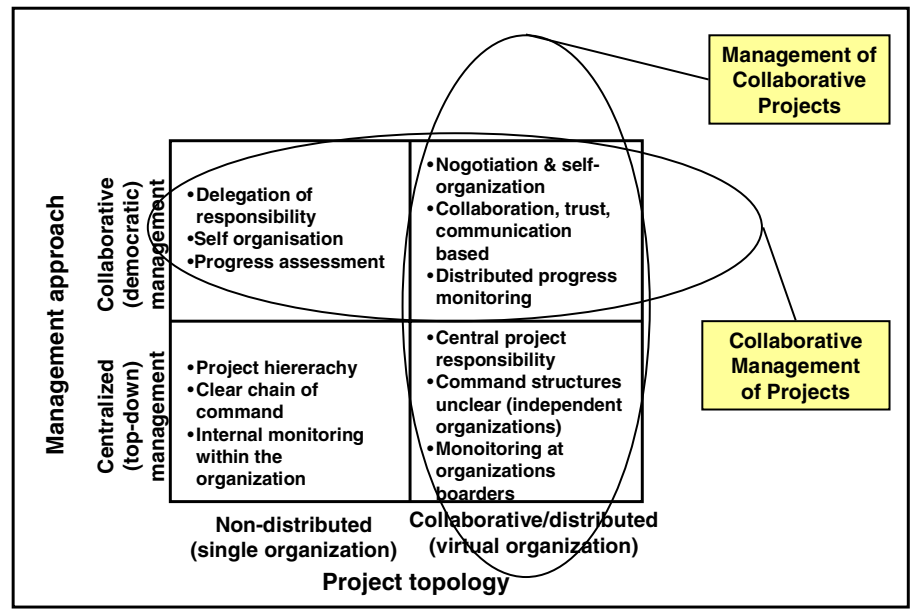

Fig. 1. Interpretations of "Collaborative Project Management"

So far, the management of collaborative projects has mainly focused on monitoring the progress of the activity and its performance. Based on the perceived measurements, the management is assumed to take suitable measure for coordinating the activities. Very little focus has been on the methods and tools to support the decision making. However, the management of inter-organizational activities is a complex task, which could be supported formally and systematically.

Also the management of inter-organizational activities has mainly been considered as transactions at the interfaces between the participating organizations. The focus has been on standardization of the information exchange in order to allow communication even between enterprise systems. Very little emphasis has been on the interactions between people and business processes. However, the collaboration is performed by people in the processes of their organizations.

In the Figure 2, the domain of collaborative management is illustrated from the perspective of management and interaction levels. Collaboration among organizations has in many cases focused on exchange of information between partners and the level of interaction has been transaction based. Further enhancement of the collaboration 


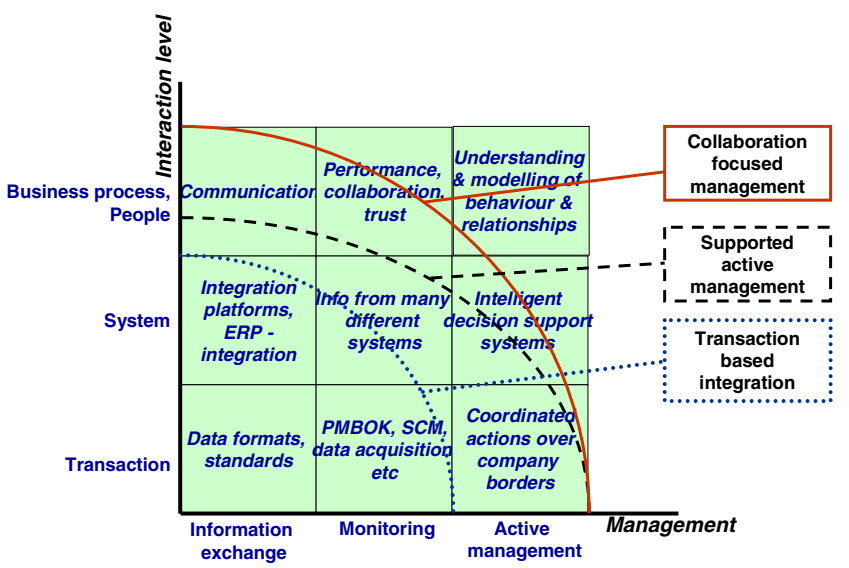

Fig. 2. Some dimensions of "Collaborative Project Management"

has resulted in system integration and solutions for interoperability between different IT systems. To support management, approaches for progress measurement have also been developed. However, the focus has been on monitoring the progress. This type of solutions is shown in the Figure 2 as "transaction based integration".

The active project management can be supported for coordinated actions over company borders, if it is supported by efficient information collection systems from the participating organizations, including monitoring of past events. In addition, intelligent decision support systems can aid for the decision making by providing proactive alarms on emerging or occurred problems. Also simulation based evaluation of different possible management actions can be performed. Approaches and solutions for this type of "supported active management" were developed and evaluated e.g. in the ECOLEAD project $[1,6,7,8]$. The solutions give real time monitoring, alarm and decision support for the relevant stakeholders [9]. In these solutions, the focus has been on the management aspects. Implicitly, there was the assumption of a manger with the final responsibility for the task or delivery, even if the stakeholders have access to relevant information about the status of the activities. In these cases, the main management challenges are found to come from the temporary nature with distribution of operations in independent but interdependent organizations with their own aim, behavior and culture $[10,11]$.

Collaborative organization culture means community, which consists of relationships between people. Values underlie organizational culture that drives organizational towards knowledge sharing [12]. So far, monitoring and information exchange have taken place as transactions mostly between intra-company systems within the supply chain. In order to enhance interaction and collaboration between business processes and people, the focus needs to shift to also include understanding and monitoring of more intangible assets, like communication, collaboration performance and trust as indicated in the Figure 2 by the area for "collaboration focused management". This approach is seen as the next step for developing the management of collaborative projects. 
The right upper corner in the Figure 2 requires strong modeling efforts and involvement of several different disciplines. This area also needs the understanding and concepts to be developed in the suggested area of "collaboration focused management".

Management focusing on business processes and relationships has to be performed through creating trust and a collaborative atmosphere, by considering risks and still relying on incomplete information. In the Figure 3, the collaborative management is illustrated. Management actions are introduced via the involved people, their communication and collaboration abilities to impact together with their mutual trust on the project performance in fulfilling the customers needs.

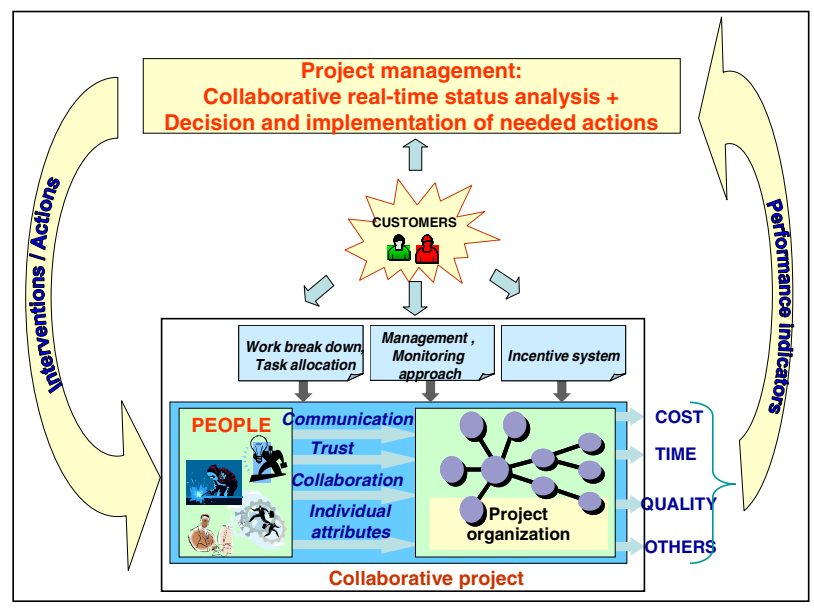

Fig. 3. Collaboration management means supporting people in their collaborative activities

In collaborative project management, decisions are made in a decentralized and democratic manner. The intangible assets and collaboration ability are even more emphasized. The coordination activities focus on the fulfillment of the customers needs and they are shown in the work break down structure with schedules and milestones. However, needed management interventions and actions aim either at enhancement of collaboration performance or reallocation of tasks.

\subsection{Intangible Assets in Collaborative Project Management}

Trust. The mutual engagement in collaboration also implies mutual trust. According to Grudzewski et al, trust is determined by the organizational culture, which is a critical factor to support collaboration [13]. In order to build trust, we need socialized individualism, universalism in work processes and operational rules, equality, scientific attitude to problem solving, law level of avoiding the uncertainty, clearness of activities $[13,14]$. Handy has defined some statements related to trust [15]:

- $\quad$ Trust is not blind.

- $\quad$ Trust needs boundaries, because unlimited trust is unrealistic

- Trust-based organizations are reengineering their work.

- $\quad$ Trust demands learning 
- $\quad$ Trust needs bonding

- Trust needs touch.

In business activities, like common projects, the inter-organizational trust also contains a rational dimension in addition to personal trust among people. Msanjila and Afsarmanesh have classified the so called fact based trust into the following categories [16]:

- Technological aspects

- $\quad$ Structural aspects

- Economical aspects contain the key counts of economical aspects for creating trust among organizations

- $\quad$ Social aspects

- Managerial aspects

Trust is a critical factor for efficient and effective communication, collaboration and knowledge creation, playing an important role in creating competitive advantage and reducing governance costs. Trust also enables open communication, information sharing, and conflict management [17].

Trust, including trust building, has become a major concern in the e-Business environment. Trust is seen as the coordinating mechanism which binds relationship together. It provides the necessary flexibility, lower transaction costs and reduces the complexity of relationship [18]. Trust management covers the activities of creating systems and methods. They allow relying parties to make assessments and decisions regarding the dependability of potential transactions involving risk. They also allow players and system owners to correctly represent their own reliability.

Leadership. Kouzes and Posner define leadership: "Leadership is ultimately about creating a way for people to contribute to making something extraordinary happen" [19]. They further describe the term, stressing that leadership can be learned.

Although there many definitions of leadership exist in the literature, most of them emphasize the support of others in the accomplishment of common objectives. Consequently, a main task of leadership is to define aims and to create a collaborative and inspiring atmosphere. A decentralized management style is usually adopted. In such an environment, culture means values, attitudes, and, understanding. A clear understanding of roles, both management's and employees', is essential, so also the organization of resources. The engagement of all participants is vital [12].

Monitoring the achievements and performance is an integrated part of collaborative actions, also leadership. The basic for performance in collaborative activities is the ability to forge relationships, the ability to communicate, and the ability for selfmotivation, i.e. networking. Mental models are internal elements, including beliefs, reactions, and internal views. Also awareness of surrounding environment and the own context are internal elements of performance management. The intention of the organization and collaborative culture is to support and develop the performance, meaning enhancing the community, which consists of relationships between individuals.

Leaders may have different styles. House and Podsakoff identified 10 different leadership styles [20]. Although management and leadership sometimes are regarded as synonyms, there have also been attempts to understand their differences [21]. One could generalize that leadership focuses mainly on the activities and the processes, when management focuses more on concrete performance measures. Naturally, both 
approaches can lead to the wanted aims. In collaborative activities, like collaborative project management, a leadership approach creating trust and a collaborating atmosphere seams more preferable to a traditional management approach, which more relies on the authority of the manager. The basic idea of leadership is team working and customer orientation [12].

\section{IT Support}

\subsection{Social Media and Project Management}

As described in chapter 2, project management is inevitably a social effort involving all relevant actors. This social aspect has to be emphasized when considering collaborative project management, where already the management itself is a social effort. Social capable IT tools and software could support the project work and management. In this chapter, some applications of social media are introduced and their possible use for project management briefly elaborated.

The term Enterprise 2.0, originally introduced by Andrew P. McAfee [22], is sometimes used to describe the collaborative nature of an enterprise, consisting of both social and networked changes to the organization, as well as implementing social software as enterprise tools. The software adaptation basically means the introduction and implementation of Web 2.0 technologies within the enterprise; including rich internet applications, providing software as a service, and using the web as a general platform. McAfee introduces six fundamental components of Enterprise 2.0 technologies to describe the qualities of the paradigm, using the acronym SLATES (search, links, authoring, tags, extensions, and signals).

Social networking capabilities can help organizations in capturing unstructured tacit knowledge. The main challenge still remains on how to differentiate meaningful and re-usable knowledge from the other content also captured in tools like blogs, online communities, and wikis. As blogs and wikis are collaboration tools, they are useful for sharing unstructured information associated with ad hoc or ongoing projects and processes. They are not good for structured informational retrieval. Business processes often rely on access to structured but distributed data and documents. Social technologies can address such complexities, share and aggregate the information, eventually enhancing enterprise-wide search. Employees often seek information, which is held internally in a variety of formats and locations, including databases, document management systems, and other repositories. Search ability is an integral feature of social technologies [23].

The unstructured information provided by social technologies is particularly useful in business processes that are not strictly pre-defined, but where people work together in an adaptive way to innovate solutions.

While introducing several positive outcomes in adapting Enterprise 2.0 technologies, McAfee also illustrates two major remaining threats. The workers may not use the adapted technologies. The employees may use the system as intended, but producing unintended outcomes.

For compact and lightweight projects, the concept of Agile Project Management (APM) has been introduced. It has been developed from the needs of, and therefore especially implemented in, software development projects. 
Traditional project management involves very disciplined and deliberate planning and control methods utilizing methodologies such as Waterfall and Capability Maturity Model (CMM), which are well-suited for long-term projects, but may actually slow down short-cycle projects. Today, business processes are more complex, interconnected, interdependent, and interrelated than earlier. In complex networks, they even reject the traditional organizational structures. The Agile Project Management methodologies are expected to respond to the needs of an agile and volatile business environment, being less complicated, iterative and incremental processes where all project stakeholders actively work together.

The main characteristics of APM are that projects are conducted collaboratively, in a small co-located team. The work is accomplished through a series of sessions, and the documentation produced is minimized as the project team relies almost exclusively on informal internal communication [24].

Developed for the software industry, the principles APM may not necessarily always apply for other industries.

Project Management 2.0 (PM2.0), or Social Project Management, is an evolution of project management practices and software built on Web 2.0 technologies and applications. Such applications include blogs, wikis and other collaborative and social software, and share characteristics like open APIs (Application Programming Interface), service oriented design and the ability to upload data and media, the ability to collaborate, share and communicate [25].

In the literature, PM2.0 is often associated with Agile Project Management or more collaborative style of project management. While PM2.0 is more about the collaborative tools, APM is more about lightweight project management practices - together they are complementary, but will as such offer no great differences to traditional project management.

Table 1. Comparison of project management approaches

\section{Traditional Project Management Project Management 2.0}

\begin{tabular}{|c|c|}
\hline Centralization of control & Decentralization of control \\
\hline Top-down planning & Bottom-up planning \\
\hline $\begin{array}{l}\text { Authoritarian, strictly controlled envi- } \\
\text { ronment }\end{array}$ & Collaborative environment \\
\hline $\begin{array}{l}\text { Implied structure, pre-defined struc- } \\
\text { ture and tasks }\end{array}$ & Emergent structures, tasking \\
\hline Limited / restricted access to the plan & Organized / unlimited access to the plan \\
\hline $\begin{array}{l}\text { Local access to information, strict } \\
\text { user restrictions }\end{array}$ & $\begin{array}{l}\text { Universal access to information, very few } \\
\text { restrictions }\end{array}$ \\
\hline $\begin{array}{l}\text { Limited communications within team, } \\
\text { separate tools }\end{array}$ & $\begin{array}{l}\text { Enhanced communications within team, } \\
\text { e.g. shared project e-mails, chats }\end{array}$ \\
\hline Separate projects & Holistic approach, resource pools \\
\hline Often complex tools & Easy to use tools \\
\hline Rigidity of tools & Flexibility of tools \\
\hline
\end{tabular}


Traditional project management places the manager in the centre of the project work. The manager collects all the information from the team, processes it and communicates to the upper management. It is hard to bring the project plan to life due to the fact that all the information on the project is passing a single person - the project manager [24].

The new generation of PM2.0 tools enables the creation of a collaborative space, giving each team member access to the full information on the project. Project progress is also visible to everyone on the team. The project manager has a visionary role choosing the direction for the project development. The tasking and structures evolve organically [25].

People and businesses are supposed to accomplish more with PM2.0 than with traditional project management tools. Insight and collaboration drive the project, instead of the management system. In Table 1, a summary of the key differences between Project Management 2.0 and traditional project management are given.

\subsection{On-Line Presence}

Widely viewed, virtual presence means being present via intermediate technologies, usually radio, telephone, television, or the internet. In addition, it can denote apparent physical appearance, such as voice, face, and body language. More narrowly, the term has been considered to denote presence on World Wide Web locations. People who browse a web site have been considered to be virtually present at web locations.

Recently, the term has developed further to mean more active presence in on-line social networks, meaning true social presence. A good example has been the emergence of businesses and state agencies in virtual worlds like Second Life.

\subsection{Software Solutions for Project Management}

Project management software is a term commonly used to cover software targeted to aid the project managers in managing their projects. This type of software can include functions for scheduling, budgeting, resource allocation, quality management, communication and documentation, as well as for administration of projects.

Most of the traditional PM solutions have focused on scheduling (tasks, durations and dependencies) and resource management (resources, availability, workload and criticality), providing functions for both planning and follow-up, in some cases also for multi-project management. Often the enterprise software suites have the functionalities for project management among their functions.

Two of the common commercial alternatives for project management software are Microsoft Project and dotProject. For viable collaborative project management, further innovations are needed. Such an innovative approach in developing support for project managers is to include "Web 2.0" applications into collaborative Project Management. This includes e.g. ability to

- $\quad$ Build on project partners distributed contribution to learning

- Collect rich user experience and shared intelligence

- Create and interact with content rather than just consume information 


\section{Applications and Further Development}

Services for Collaborative Project Management have been studied e.g. in the COIN project (http://www.coin-ip.eu/) and requirements for development have been collected. The requirements definition is based on the analysis of the operations in several industrial companies. One of them is a global market leader in the process industry. The company provides engineering and project implementation services for investment projects worldwide, maintenance engineering and local services to process plants. According to the company outlook, future success in Europe will build on the combination of two paradigms:

- Fully automated and IT supported engineering process

- Totally networked and efficient global operation

The fully automated and IT supported engineering process means extreme and wide usage of emerging ICT technology resulting in radical breakthrough in efficiency, automated operations in design and project implementation with efficient tools and methods.

Totally networked and efficient global operations take full advantage of the efficient usage of core competencies in networked organizations. The work is distributed between the most competent and cost-efficient project partners. Agreed and shared work processes and operational procedure support social and participative project execution. To support the above mentioned paradigms, the following topics are selected for further development:

- $\quad$ Shared working practices - Project Alignment

- Delegated and participatory project execution - Communication through tasks

Project alignment is the process of ensuring that key stakeholders share a common understanding of the project work processes, operational procedures, objectives and plans. Alignment is not just a matter of agreement on certain project working habits, norms and styles. The achievement of a good level of alignment often requires participation in a learning process.

To build and increase the project alignment level, there is a need to analyze and measure the working and experience level at the project partners. Based on the alignment capabilities a suitable learning environment can be established. Consequently, the measurement of partner's alignment status and an interactive learning environment are the two building blocks in boosting project alignment.

The Participative Project Alignment Booster, with components to be implemented as web-services and currently under development, will contain the following services:

- Participative definition of maturity model and best practices.

- Project specific work process and operating instructions.

- Identification of alignment training needs

- Project interactive e-learning space

The paradigm of totally networked and efficient global operation requires support for delegated and participatory project execution - Communication through tasks. The approach of totally networked and efficient global operation takes advantage of efficient 
usage of the core competencies of networked organizations. Agreed and shared operational procedure support social and participative project execution. The basic underlying principle is that the work is broken down to a detailed task level. The planning of tasks on the lowest level is accomplished by the person actually performing the work. In that way, the defined task sizes, work content and duration will be fully understandable and realistic estimations about their performance can be done.

Acknowledgements. The paper is based on work performed in the Integrated project ECOLEAD funded by the European Community under the Framework programme 6 (IP 506958) and the Integrated project COIN funded by the European Community under the Framework programme 7 (Grant Agreement Number 216256).

\section{References}

1. Camarinha-Matos, L.M., Afsarmanesh, H., Ollus, M. (eds.): Methods and Tools for Collaborative Networked Organizations. Springer, New York (2008)

2. Graham, P. (ed.): Mary Parker Follett: Prophet of Management. Harvard Business School Press (1995) ISBN: 0-87584-736-6

3. Caupin, G., Knoepfel, H., Koch, G., Pannenbäcker, K., Pérez-Polo, F., Seabury, C.: ICP. IPM Competence Baseline. Version 3.0. IPMA International Project Management Association (2006) ISBN: 0-9553213-0-1

4. Project Management Institute: A Guide to the Project Management Body of Knowledge (PMBOK® Guide) - Third Edition, ISBN10: 193069945X, ISBN13: 9781930699458

5. APM Body of Knowledge. 5th Edition Paperback (2006) ISBN: 1-903494-13-3

6. Camarinha-Matos, L.M., Afsarmanesh, H. (eds.): Collaborative Networks: Reference Modeling. Springer, New York (2008)

7. Jansson, K., Karvonen, I., Ollus, M., Paganelli, P., Stewens, R., Negretto, U.: Real Time Virtual Organisations Management. In: Cunningham, P., Cunningham, M. (eds.) Innovation and the Knowledge Economy - Issues, Applications, Case Studies. IOS Press, Amsterdam (2005)

8. Jansson, K., Karvonen, I., Ollus, M., Negretto, U.: Governance and management of virtual organizations. In: Camarinha-Matos, L.M., Afsarmanesh, H., Ollus, M. (eds.) Methods and Tools for Collaborative Networked Organizations. Springer, Heidelberg (2008)

9. Negretto, U., Hodík, J., Král, L., Mulder, W., Ollus, M., Pondrelli, L., Westphal, I.: VOManagement Solutions; VO Management e-Services. In: Camarinha-Matos, L.M., Afsarmanesh, H., Ollus, M. (eds.) Methods and Tools for Collaborative Networked Organizations. Springer, Heidelberg (2008)

10. Ollus, M., Jansson, K., Karvonen, I.: On the Management of Collaborative Networked Organizations. In: Cunningham, P., Cunningham, M. (eds.) Conference Proceedings from IST-Africa 2006. IIMC International Information Management Corporation (2006)

11. Ollus, M., Jansson, K., Karvonen, I.: On the management of collaborative SME networks. In: The proceedings of COA 2007 - 8th IFAC Symposium on Cost-Oriented Automation, Habana, Cuba (2007)

12. Aarrevaara, T.: Johdatus organisaatioteoriaan ja johtamiseen (In Finnish: Introduction to organizational theory and management) (2000)

13. Grudzewski, W.M., Hejduk, I.K., Sankowska, A., Wantuchowicz, M.: Cultural determinants of creating modern organisations - the role of trust. In: PRO-VE 2008. 9th IFIP Working Conference on Virtual Enterprises, pp. 323-332 (2008) 
14. Abuelmaatti, A., Rezgui, Y.: Virtual team wotking: Current issues and directions for the future. In: PRO-VE 2008. 9th IFIP Working Conference on Virtual Enterprises, pp. 351$360(2008)$

15. Handy C.: Trust and Virtual Organization. Harward Business Review (May-June 1995)

16. Msanjila, S., Afsarmanesh, H.: Inter-Organizational Trust in VBEs. In: Camarinha-Matos, L.M., Afsarmanesh, H., Ollus, M. (eds.) Methods and Tools for Collaborative Networked Organizations. Springer, New York (2008)

17. Afsarmanesh, H., Camarinha-Matos, L.M.: A Framework for Management of Virtual Organization Breeding Environments. In: PRO-VE 2005, pp. 35-48 (2005)

18. Ren, Z., Hassan, T.M., Cater, C.D.: Trust building for SMEs through an e-Engineering Hub. In: PRO-VE 2005. 6th IFIP Working Conference on Virtual Enterprises, pp. 157-166 (2005)

19. Kouzes, J.M., Posner, B.Z.: The Leadership Challenge, 4th edn. (2008) ISBN: 978-0-78798491-5

20. House, R., Podsakoff, P.M.: Leadership Effectiveness: Past Perspectives and Future Directions for Research. In: Greenberg, J. (ed.) Organizational Behavior: The State of the Science. Erlbaum, Hillsdale (1994)

21. Bennis, W.: On Becoming A Leader. Random Century (1989) ISBN 0-7126-9890-6

22. McAfee, A.P.: Enterprise 2.0: The Dawn of Emergent Collaboration. MIT Sloan Management Review 47(3), 21 (Spring 2006)

23. Stenmark, D.: How intranets differ from the web: organisational culture's effect on technology. In: Proceedings of ECIS 2005, Regensburg, Germany, May 26-28 (2005)

24. Haas, K.P.: The Blending of Traditional and Agile Project Management. PM World Today IX(V) (May 2007),

http: / / www. pmforum. org/library/tips / 2007 / PDFs / Haas-5-07. PDF

25. Filev, A.: Bridging the Three Gaps in Project Management. Writing on Project Management 2.0 blog at Wrike (March 25, 2008),

http: / /www. wrike.com/projectmanagement/03/25/2008/

Bridging-the-Three-Gaps-in-Project-Management

26. Lynch, C.: Project Management 2.0. Project Management Planet (September 21, 2007), http: //www.projectmanagerplanet.com/leadership/article.php/ 37010312007 